\title{
Epithelial atypia in biopsies performed for microcalcifications. Practical considerations about 2,833 serially sectioned surgical biopsies with a long follow-up
}

\author{
Isabelle de Mascarel • Gaëtan MacGrogan • \\ Simone Mathoulin-Pélissier • Anne Vincent-Salomon • \\ Isabelle Soubeyran • Véronique Picot • \\ Jean-Michel Coindre • Louis Mauriac
}

Received: 13 October 2006 /Revised: 25 January 2007 / Accepted: 18 March 2007 / Published online: 6 June 2007

(C) Springer-Verlag 2007

\begin{abstract}
This study analyzes the occurrence of epithelial atypia in 2,833 serially sectioned surgical breast biopsies (SB) performed for microcalcifications (median number of blocks per SB:26) and the occurrence of subsequent cancer after an initial diagnosis of epithelial atypia (median followup 160 months). Epithelial atypia (flat epithelial atypia, atypical ductal hyperplasia, and lobular neoplasia) were found in $971 \mathrm{SB}$, with and without a concomitant cancer in $301(31 \%)$ and $670(69 \%) \mathrm{SB}$, respectively. Thus, isolated epithelial atypia were found in 670 out of the $2,833 \mathrm{SB}$ (23\%). Concomitant cancers corresponded to ductal carcinomas in situ and micro-invasive (77\%), invasive ductal carcinomas not otherwise specified (15\%), invasive lobular carcinomas (4\%), and tubular carcinomas (4\%). Fifteen out
\end{abstract}

I. de Mascarel $(\bowtie) \cdot$ G. MacGrogan • I. Soubeyran •

J.-M. Coindre

Department of Pathology, Institut Bergonié,

Regional Cancer Center,

Bordeaux, France

e-mail: mascarel@bergonie.org

S. Mathoulin-Pélissier

Department of Biostatistics, Institut Bergonié,

Regional Cancer Center,

Bordeaux, France

A. Vincent-Salomon $\cdot$ V. Picot

Department of Pathology, Institut Curie,

Regional Cancer Center,

Paris, France

L. Mauriac

Department of Medical Oncology, Institut Bergonié,

Regional Cancer Center,

Bordeaux, France of the 443 patients with isolated epithelial atypia developed a subsequent ipsilateral $(n=14)$ and contralateral $(n=1)$ invasive cancer. The high slide rating might explain the high percentages of epithelial atypia and concomitant cancers and the low percentage of subsequent cancer after a diagnosis of epithelial atypia as a single lesion. Epithelial atypia could be more a risk marker of concomitant than subsequent cancer.

Keywords Breast $\cdot$ Epithelial atypia $\cdot$ Lobular neoplasia . Atypical ductal hyperplasia $\cdot$ Cancer

\section{Introduction}

Breast biopsies for infraclinical lesions are more frequent with mammographic screening programs, but the distribution of the corresponding histological lesions and their associations are still imprecise. Difficulties encountered in following up patients without cancer account for the fact that the clinical significance of certain non-malignant lesions and the management of patients are still debated. Moreover, the problem of surgical biopsy sampling has never been fully investigated and has added additional confusion in appreciating the distribution and clinical significance of such lesions. In 1981, breast epithelial atypia were hardly mentioned and not clearly defined in the World Health Organization/International Union Against Cancer (WHO/UICC) histologic classification of breast tumors [73]. The histologic classification of noncancerous lesions has been mainly based on studies analyzing for each lesion the associated risk of subsequent cancer. These studies were initiated by the survival studies of Dupont and 
Page $[15,46]$ based on lesions discovered by palpation before the era of mammography. Thereafter, further studies $[6,9,17,24,31,51,62,67]$ substantiated these results, which were ratified in 2003 by the new American Joint Committee on Cancer (AJCC)/UICC classification of breast tumors [70]. Schematically, this classification differentiates benign epithelial lesions (usual ductal hyperplasia and other lesions) from atypical lesions of ductal or lobular type. Although this historical classification is challenged by a new classification [68], it remains the most widely used in practice. Interestingly, the occurrence of epithelial atypia was low in Page's study [46] and has increased with mammographic screening programs $[60,66]$ and with the development of percutaneous large core needle biopsy (CNB) methods using stereotactic mammography or ultrasound guidance. At present, CNB is frequently used for the initial evaluation of clinically occult breast lesions, thus generating dilemma for the subsequent management of certain noncancerous lesions. At our institution, surgical biopsies (SB) have always been managed in the same way, and most patients with atypical and malignant lesions have been followed. The objectives of our work were to analyze the occurrence of epithelial atypia and their association with a concomitant cancer in a large series of SB performed for microcalcifications without a palpable tumor and to assess the subsequent cancer probability in the group of patients with an initial diagnosis of epithelial atypia. Finally, we provide some practical considerations for the management of patients with epithelial atypia in this era of mammographic screening and CNB.

\section{Materials and methods}

\section{Selection of patients}

At Institut Bergonié, from January 1975 to December 2002, 3,166 breast biopsies for diagnostic purposes, 2,833 SB and $333 \mathrm{CNB}$, were performed for microcalcifications without any palpable mass in 2,708 patients (mean age 51.8 years, range 19.7-81 years). Among them, 248 (9\%) had several biopsies in the same or contralateral breast. Since 1998, microcalcifications have been classified according to the classifications of the American College of Radiology [2]. SB for diagnostic purposes were defined before 1998 by the absence of a preoperative diagnosis based on the clinicalmammographic-cytologic triplet and by the absence of a positive frozen section and, since 1998, by the presence of epithelial atypia on CNB. Excluded from this study were 132 cancers and 139 non-atypical benign lesions diagnosed on CNB as well as 49 re-excisions performed elsewhere than in our center. Thus, 2,833 SB in 2,375 patients were available for analysis, among which 13 corresponded to re- excision after a CNB with epithelial atypia. Since 1989, needle localization, intraoperative specimen radiography, and post-excisional biopsy mammography have been performed in most cases.

Surgical biopsies and tissue sampling: serial macroscopic sectioning

SB was removed in one fragment and measured more than $3 \mathrm{~cm}$ in $94 \%$ of the cases (mean size $60 \mathrm{~mm}, 5-250 \mathrm{~mm}$ ). For SB margin assessment, either the surface of the specimen was inked or the surgeon during the same operation removed additional tissue in the remaining cavity after excision of the specimen (surgical margins). After fixation in Holland Bouin, SB and margin specimens were serially sectioned in their entirety into numbered slices every $2 \mathrm{~mm}$ [12]. In most cases (89\%), careful macroscopic examination of the specimen failed to reveal any lesion. Each numbered slice was put in as many numbered separate cassettes as necessary and paraffin-embedded in sequence. The median number of blocks per SB was 26 (from 2 to 180 ) and 8 (from 1 to 44 ) for surgical margins. Each block was examined on one hematoxylin-eosin-safran stained slide.

\section{Classification of lesions and review of slides}

Since 1975, all patients have been prospectively included in our clinical, histologic, and biologic database by senior pathologists (IM, GMG, IS, JMC). For each SB and each lesion, we prospectively entered in our pathologic database morphological descriptive criteria by using 65 pathological items for noncancerous lesions and 181 for cancers. Definitions and terminologies given in the literature were used to report columnar cell lesions (CCL), non-atypical ductal hyperplasia, atypical ductal hyperplasia, ductal carcinoma in situ (DCIS), and lobular carcinoma in situ (LCIS) $[1,4,7,10,17,19,21-28,38,43-45,47,49,50$, $56,59,61,69,72,74,75]$. The interest of our database was to collect morphological descriptive criteria of nearly all the breast lesions without labeling them. In fact, labels and definitions of breast lesions have varied throughout the past 30 years, while neither lesions nor their corresponding descriptive criteria (i.e., size, type, architecture, cellular and nuclear features, etc...) have changed. The only changes during this period were the definitions and/or the names given to these lesions. As we have listed for each lesion all the corresponding descriptive criteria among the 236 available items, we have been able to reclassify each lesion according to the "new" criteria recommended by referent authorities for a new definition, by selecting in our database the "new" correspondent descriptive criteria corresponding to this new definition. Consequently, this provided a 
homogeneous approach to the pathological lesions at the time of our study. For example, low-grade DCIS $\leq 2 \mathrm{~mm}$ have been reclassified as atypical ductal hyperplasia/ductal intraepithelial neoplasia (ADH/DIN) 1B $(n=30)$ according to the new AJCC/UICC classification of breast tumors [70], and lesions that we used to term before 1997 [71] as clinging carcinoma of the monomorphic type [4] have been reclassified as flat epithelial atypia (FEA)/DIN 1A or columnar cell change (CCC) with atypia $(n=84)$ [61]. About half of these 114 cases have been systematically reviewed by one (IM) or two senior pathologists (IM and GMG or IS), and there was a complete concordance between the second review and the initial descriptive criteria listed in the database. Similarly, lesions that we used to name LCIS before 1997 have been renamed lobular neoplasia (LN) since 1997, corresponding either to atypical lobular hyperplasia (ALH) or to LCIS. On the contrary, all the cases with micropapillary lesions were reviewed $(n=$ 155) because there was no item corresponding to precise descriptive criteria of micropapillations (number, topography around the duct, type).

\section{Atypical ductal hyperplasia: definition and sizing}

Among the group of ADH/DIN 1B, we individualized two morphologic types of ADH. Neither had any high-grade cytological atypia or necrosis.
$A D H$ "mimicking DCIS" (Fig. 1). In this type, architectural atypia were qualitatively insufficient to allow a diagnosis of DCIS, therefore this "mimicking" DCIS lesion was classified as ADH whatever its size. Tufts and short micropapillations formed by cells had a broad base and were cohesive. There was no polarization of cells, i.e., no true cribriform spaces. Pseudo-cribriform patterns comprised irregular or relatively round microlumina with incomplete polarization of surrounding epithelial cells. Cellular bridges were wavy without any cellular polarization. Cells corresponded either to columnar cells with uniform ovoid to elongated nuclei or to cells with a slight increase in the nuclear/cytoplasmic ratio with more or less distinct cell borders and round or ovoid nuclei. These cells were sometimes admixed in the same lesion displaying a morphological gradient, but there was no regular arrangeent. Nuclear chromatin was evenly dispersed, homogeneous, or slightly marginated, and nucleoli were inconspicuous. Apical snouts, intraluminal secretions, and psammoma-type calcifications were frequently present.

ADH corresponding to "mini DCIS" (Fig. 2). In this type, architectural and cytologic atypia corresponded to a low-grade DCIS but were quantitatively insufficient to allow a diagnosis of DCIS, therefore this "mini" DCIS lesion was classified as ADH when $\leq 2 \mathrm{~mm}$. Tufts and short micropapillations had a tight base, were present on over all the periphery of the duct, and were non-cohesive with small
Fig. 1 a-d. ADH "mimicking DCIS." a Tufts and short micropapillations with a broad base. b Pseudo-cribriform spaces. c Microlumen with incomplete polarization of surrounding epithelial cells. $\mathbf{d}$ Cellular bridges without cellular polarization. Cells are parallel to the axes (arrows)
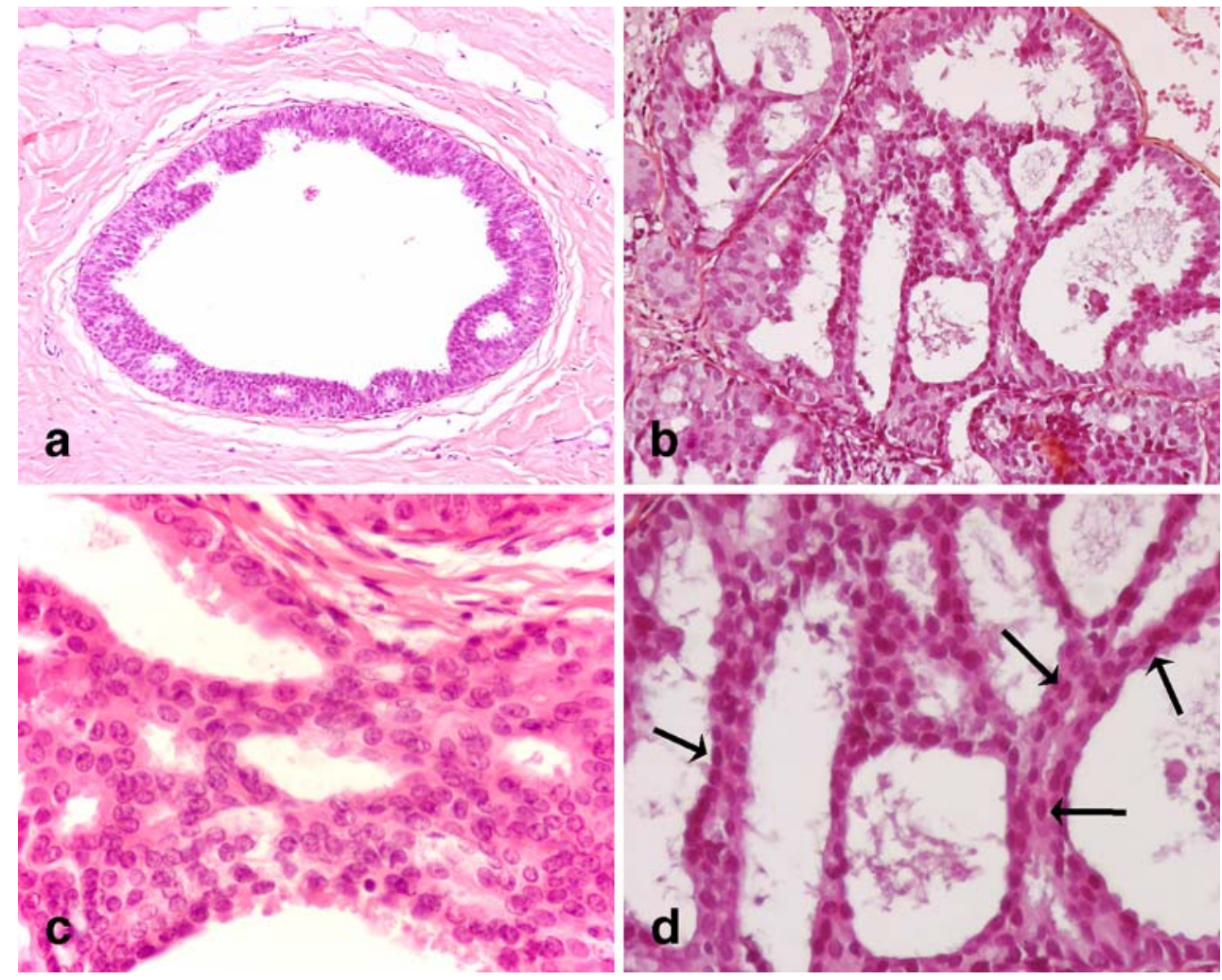

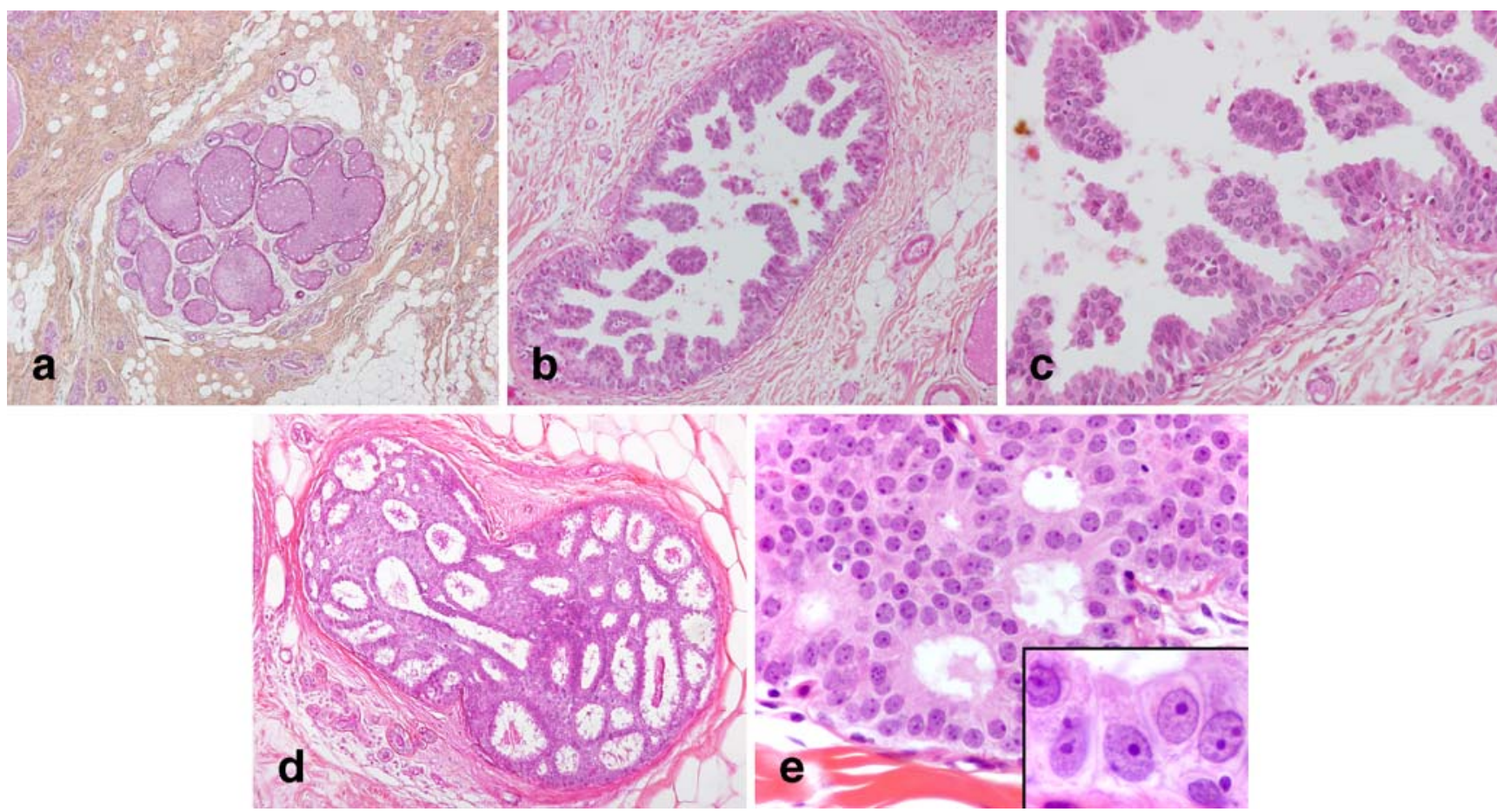

Fig. 2 a-e. ADH corresponding to "mini DCIS." a A solid mini DCIS focus measuring less than $2 \mathrm{~mm}$ in one TDLU. b Tufts and short micropapillations over the entire periphery of the duct with small

free papillary tufts in the lumen. c Short micropapillations with a tight base. d True cribriform spaces. e Microlumen with complete polarization of surrounding epithelial cells

free papillary tufts in the lumen. There were true cribriform patterns with a polar organization of cells around glandular spaces and/or variants of cribriform patterns (i.e., trabecular bars, cartwheel formations, and Roman bridges, Fig. 3) with polarized cells arranged perpendicular to the axes. Some solid areas with regular arrangement of cells were also present. Cells were often small, monomorphous, sometimes without a columnar change, with a distinct cytoplasmic membrane and a spaced regular round nucleus with uniformly dispersed chromatin without prominent nucleoli. Intraluminal secretions and calcifications (amorphous or psammoma-type) were also frequently present (Fig. 4). When one mini DCIS focus was found in one partially or completely involved duct/ductular crosssections in one terminal ductal lobular unit (TDLU), it was classified as ADH when it measured $\leq 2 \mathrm{~mm}$ and as DCIS when it measured $>2 \mathrm{~mm}$. When there were several foci of "mini" DCIS in close duct/ductular cross-sections in the same TDLU or in TDLUs located in the same field at low power magnification (2.5), the lesion was classified as $\mathrm{ADH}$ when its size, i.e., its largest diameter, was $\leq 2 \mathrm{~mm}$ and as DCIS when $>2 \mathrm{~mm}$. When there were several foci of "mini" DCIS in distant duct/ductular crosssections in the same TDLU or in close TDLUs, the size of each focus was assessed separately. FEA, rare and scattered single micropapillations, and cribriform variants

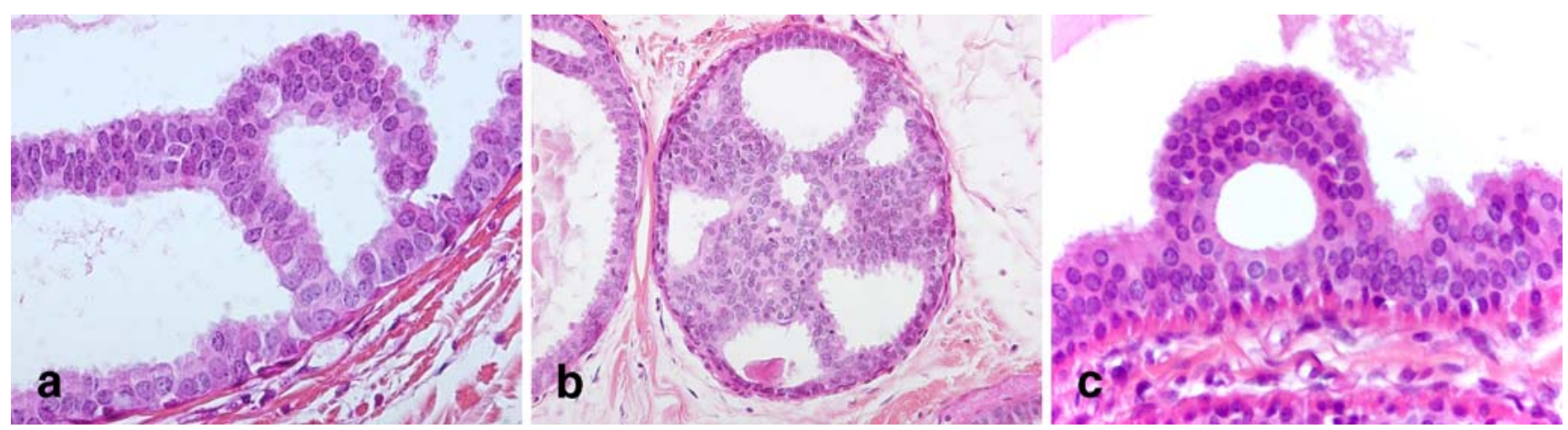

Fig. 3 a-c. Variants of cribriform patterns. Polarized cells arranged perpendicular to the axes. a Trabecular bars. b Cartwheel formations. c Roman bridges 
Fig. 4 a and b. a Mild cytologic atypia. b Columnar cells with uniform ovoid nuclei, intraluminal calcifications
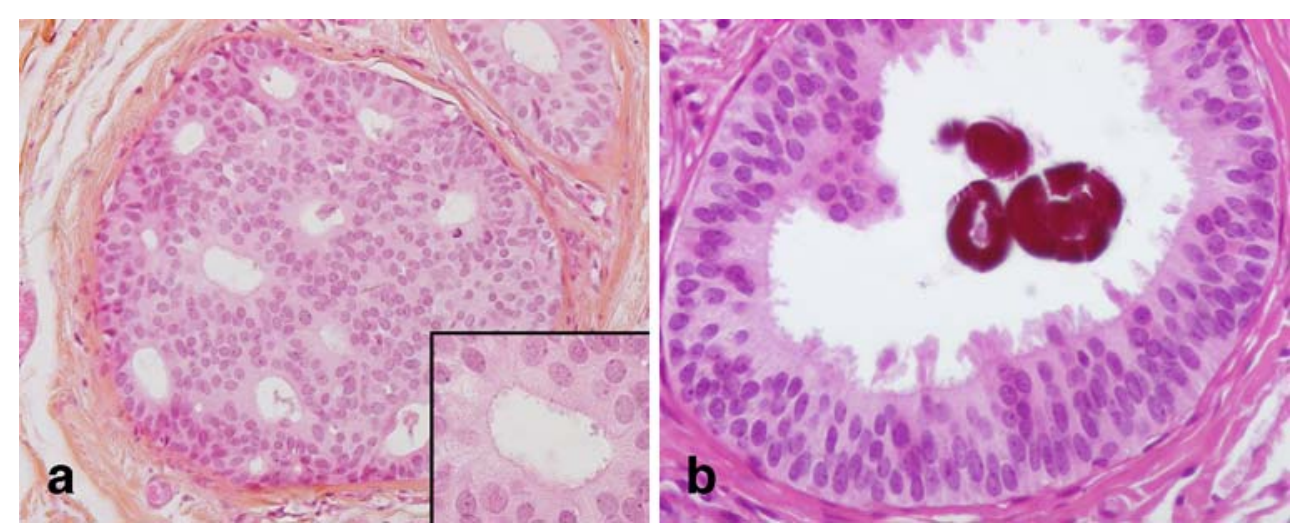

were not taken into consideration for sizing, even if located in the same TDLU.

FEA were present either as a single lesion or in association with ADH in the same TDLU and since 1997 have been included in the ADH group. The distinction of FEA from columnar change without atypia was based on the criteria given by the WHO for the definition of FEA. Furthermore, columnar change without atypia was characterized by one or two layers of columnar cells without nuclear atypia, i.e., no increase in the nuclear/cytoplasmic ratio, no prominent nucleoli. Nevertheless, some cases of columnar change with progesterone impregnation, especially in the second part of the cycle, might display a lobular distension with a secretory material and large nuclei with prominent nucleoli. In such cases, myoepithelial cells displayed the same alterations with clarified cytoplasms, thus facilitating the diagnosis. The distinction of $\mathrm{ADH}$ mimicking DCIS from usual hyperplasia (UDH) was based on morphological criteria. Architectural pattern and cytologic criteria of usual ductal hyperplasia were easy to identify in most cases. UDH corresponded to a proliferation of epithelial cells in solid or fenestrated areas without any polarization of surrounding cells. Cells were haphazardly arranged with overlapping nuclei or were parallel with characteristic streamings. They were elongated or pseudo epithelioid, but there was no columnar metaplasia. Cytoplasms were more or less abundant with indistinct borders. Nuclei had irregular size and shape and sometimes contained a prominent eosinophilic inclusion. In some rare cases, immunohistochemical staining with cytokeratin $5 / 6$ [41] was used and was negative in ADH mimicking DCIS and strongly positive in UDH. In some lesions, differential diagnosis between ADH and low-grade DCIS was all the more difficult because there were intermediate and intricated morphological aspects in the same TDLU. In practice, diagnosis of micropapillary lesions was often difficult. Extensive micropapillary lesions were classified as DCIS when quantitative and qualitative criteria were simultaneously present, i.e., lesion sizing more than $2 \mathrm{~mm}$ corresponding to micropapillations with a tight base over the entire periphery of the ducts. Additional sections could be useful for demonstrating more or less qualitative or quantitative diagnostic criteria. When malignancy remained equivocal, the case was classified as $\mathrm{ADH}$. When a concomitant cancer was diagnosed, histologic size was assessed, and in DCIS, the percentage of blocks with cancer ("positive blocks") was specified [13]. Presence and topography of microcalcifications were also assessed. Lastly, when FEA and/or "mimicking" DCIS foci were found on excision margins of a SB with DCIS, a further surgical resection was not performed.

Follow-up of patients with epithelial atypia as a single lesion

There were 443 patients with epithelial atypia in one or several SB, without any previous or synchronous carcinoma in the same or contralateral breast and treated by biopsy alone (median follow-up 160 months, 7 to 315 ). Only 28/443 (6\%) were lost to follow-up. Among the 415 other patients, 180 were monitored at our institute and 235 outside by correspondent specialists working in close relationship with our institute. All patients received a clinical examination and mammography once a year. When a new biopsy was necessary, it was performed at our institute.

\section{Statistical analyses}

Comparison of clinical and histologic characteristics was conducted by using the chi-square test. For women with epithelial atypia, the probability of developing in situ or invasive cancer was calculated from the date of the first biopsy to the earliest event: breast cancer (ipsi- or contralateral), death, or last contact (last consultation for the group monitored at our institute and checkpoint date, i.e., 1 March 2004, for the others). Probabilities were calculated according to the Kaplan-Meier method (SPSSv11). 


\section{Results}

Occurrence of epithelial atypia in the 2,833 surgical biopsies

Epithelial atypia were recorded in 971/2,833 SB (34\%). They were found with and without a concomitant cancer in $301 / 971(31 \%)$ and $670 / 971(69 \%)$ of the cases, respectively. Thus, isolated epithelial atypia were found in $23 \%$ of the cases ( 670 out of the $2,833 \mathrm{SB}$ ). Calcifications were present at histologic examination in $98.6 \%$ of SB with cancer and were located in benign, cancerous, and both lesions in 10,39 , and $51 \%$ of the cases, respectively. In several cases, cancerous foci without any microcalcifications were located at points distant from those with calcifications detected by needle localization.

Types of epithelial atypia

Among the 971 SB with epithelial atypia, there were 101 SB with FEA as a single lesion (11\%), 342 (35\%) with ADH, 223 (23\%) with LN, and 305 (31\%) with ADH and LN. Thus, ADH was encountered in 647/971 SB (66\%).

Types of cancers associated with epithelial atypia

Cancers associated with epithelial atypia corresponded to DCIS and micro-invasive carcinoma (DCIS-MI) in 233 cases $(77 \%)$. Among invasive carcinomas $(n=68)$, there were $13(9 \%)$ lobular and $11(6 \%)$ tubular carcinomas (Table 1). Cancers were small $(\leq 5 \mathrm{~mm}$ in $46 \%$ of invasive carcinomas, fewer than half of the blocks positive in $76 \%$ of DCIS). They were non-high grade in 78 and $67 \%$ of DCIS and invasive carcinoma, respectively. In most cases, $\mathrm{ADH}$ and cancer were situated close to each other. FEA alone were less frequently associated with a concomitant cancer than $\mathrm{ADH}$ and/or $\mathrm{LN}\left(p=5 \times 10^{-4}\right)$.
Cancers without epithelial atypia (malignancy alone)

There were 821 malignant SB without epithelial atypia [590 micro-invasive carcinomas, 206 infiltrating ductal carcinomas (IDC), and 25 infiltrating lobular carcinomas (ILC)].

Subsequent cancer in patients with an initial diagnosis of epithelial atypia as a single lesion

At 5 and 10 years, the probabilities of developing invasive breast cancer in the group of 443 patients with epithelial atypia were $2.8 \%$ [95\% CI $=1.4$ to 5.5$]$ and $5.5 \%[95 \% \mathrm{CI}=$ 3.3 to 9.9 ], respectively (Fig. 5). Among the 18 subsequent carcinomas, 15 were invasive (11 IDC and 4 ILC), and 3 corresponded to DCIS. Most subsequent carcinomas were encountered in the homolateral breast $(n=14)$ and before 10 years $(n=16)$. Seven carcinomas occurred in the group of patients with an initial diagnosis of $\mathrm{LN}$, in the same $(n=$ $5)$ or contralateral $(n=2)$ breast. They corresponded to infiltrating ductal $(n=6)$ or lobular $(n=1)$ carcinomas. The interval of development was 4, 5, $6(n=2), 9$, and $12(n=2)$ years. Seven carcinomas occurred in the group of patients with an initial diagnosis of $\mathrm{ADH}$, in the same $(n=3)$ or contralateral $(n=4)$ breast. They corresponded to DCIS $(n=$ $2)$ and to infiltrating ductal $(n=4)$ or lobular $(n=1)$ carcinomas. The interval of development was 1, 2, 3 $(n=3), 9$, and 12 years. Four carcinomas occurred in the group of patients with an initial diagnosis of $\mathrm{ADH}$ associated with $\mathrm{LN}$, in the same $(n=3)$ or contralateral $(n=1)$ breast. They corresponded to DCIS $(n=1)$ and to infiltrating ductal $(n=2)$ or lobular $(n=1)$ carcinomas. In the four cases, the interval of development was 4 years. There was no subsequent carcinoma in the group of patients with FEA.

Table 1 Types of concomitant cancers $(n=301)$ in the 971 surgical biopsies with epithelial atypia

\begin{tabular}{|c|c|c|c|c|c|c|c|c|}
\hline \multirow{3}{*}{$\begin{array}{l}\text { Epithelial atypia } \\
\text { Without cancer }\end{array}$} & \multirow{2}{*}{\multicolumn{2}{|c|}{$\frac{\text { FEA }(n=101)}{\text { No. of cases }(\%)}$}} & \multirow{2}{*}{\multicolumn{2}{|c|}{$\frac{\mathrm{ADH}(n=342)}{\text { No. of cases }(\%)}$}} & \multirow{2}{*}{\multicolumn{2}{|c|}{$\begin{array}{l}\text { LN }(n=223) \\
\text { No. of cases }(\%)\end{array}$}} & \multirow{2}{*}{\multicolumn{2}{|c|}{$\frac{\mathrm{ADH}+\mathrm{LN}(n=305)}{\text { No. of cases }(\%)}$}} \\
\hline & & & & & & & & \\
\hline & 84 & 83 & 220 & 64 & 139 & 62 & 227 & 74 \\
\hline With cancer & 17 & 17 & 122 & 36 & 84 & 38 & 78 & 26 \\
\hline DCIS/DCIS-MI & 12 & 12 & 103 & 30 & 58 & 26 & 60 & 20 \\
\hline IDC/NOS & - & - & 16 & 4.7 & 17 & 8 & 11 & 3 \\
\hline ILC & 1 & 1 & 1 & 0.3 & 6 & 3 & 5 & 2 \\
\hline $\mathrm{TC}$ & 4 & 4 & 2 & 1 & 3 & 1 & 2 & 1 \\
\hline
\end{tabular}

FEA Flat epithelial atypia; $A D H$ atypical ductal hyperplasia; $L N$ lobular neoplasia; DCIS ductal carcinoma in situ; DCIS-MI DCIS with microinvasion; IDC infiltrating ductal carcinoma; ILC infiltrating lobular carcinoma; TC tubular carcinoma 


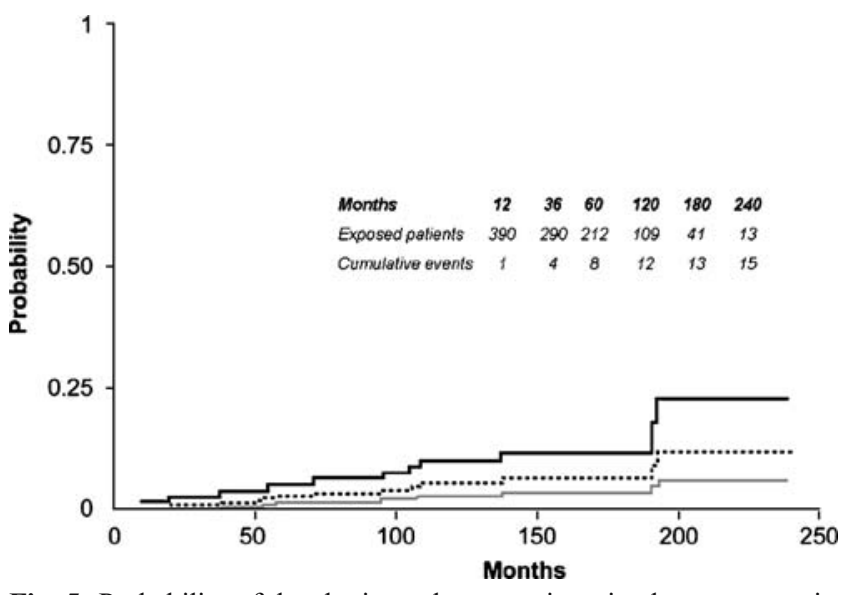

Fig. 5 Probability of developing subsequent invasive breast cancer in the group of 415 patients with epithelial atypia (dotted line: confidence interval 95\%)

\section{Discussion}

Application of the WHO classification: practical considerations

For a long time, DCIS was diagnosed even if the characteristic features were found in only one ductal space [6]. Thereafter, some authors introduced quantitative criteria for distinguishing between ADH and DCIS [46, 67], while others [23] rejected them. More recently, Rosen [57-59] and Schnitt and Vincent-Salomon [61] described CCL comprising $\mathrm{CCC}$ and columnar cell hyperplasia $(\mathrm{CCH})$ with and without atypia. Nasser [40] challenged this classification based on columnar shape and limited the group of lesions to proliferations characterized by a lowgrade atypicality, "atypical columnar cell lesions," (ACCL) rather by a columnar cell configuration. In the WHO classification, ADH includes various not clearly defined types of lesions (Table 2). On one hand, there are lesions with arcades, moundings, and micropapillary formations, but without any true cribriform/complex architectural patterns [34]. This type of ADH corresponds to the $\mathrm{CCH}$ with atypia of Schnitt and Vincent-Salomon [61] termed category 3 in Simpson's study [51], to the definition of ADH by Koerner [34] and to ADH "mimicking" DCIS in our study. On the other hand, there are lesions displaying architectural and cytologic atypia. This type of ADH corresponds to the complex architectural pattern with cytologic and architectural atypia of Schnitt and VincentSalomon [61] termed category 5 in Simpson's study [64], to the definition of "microfocus of DCIS" by Koerner [34] and to "mini DCIS" in our study. In Simpson's study, the ADH/ category 5 contained chromosomal changes and the same total mean number of changes to that observed in DCIS/ DIN IC, unlike the other CCL. Lastly, because there is still no consensus for measuring $\mathrm{ADH}$, there is no clear-cut distinction between ADH and DCIS, and the cut-off at 2 or 3 [52] $\mathrm{mm}$ or at two completely involved spaces [70] seems arbitrary. While awaiting a definitive molecular classification, the simplest attitude could be recommended in routine

Table 2 Terminologies used for intraductal proliferative lesions with low-grade cytologic atypia, so-called atypical columnar cell lesions

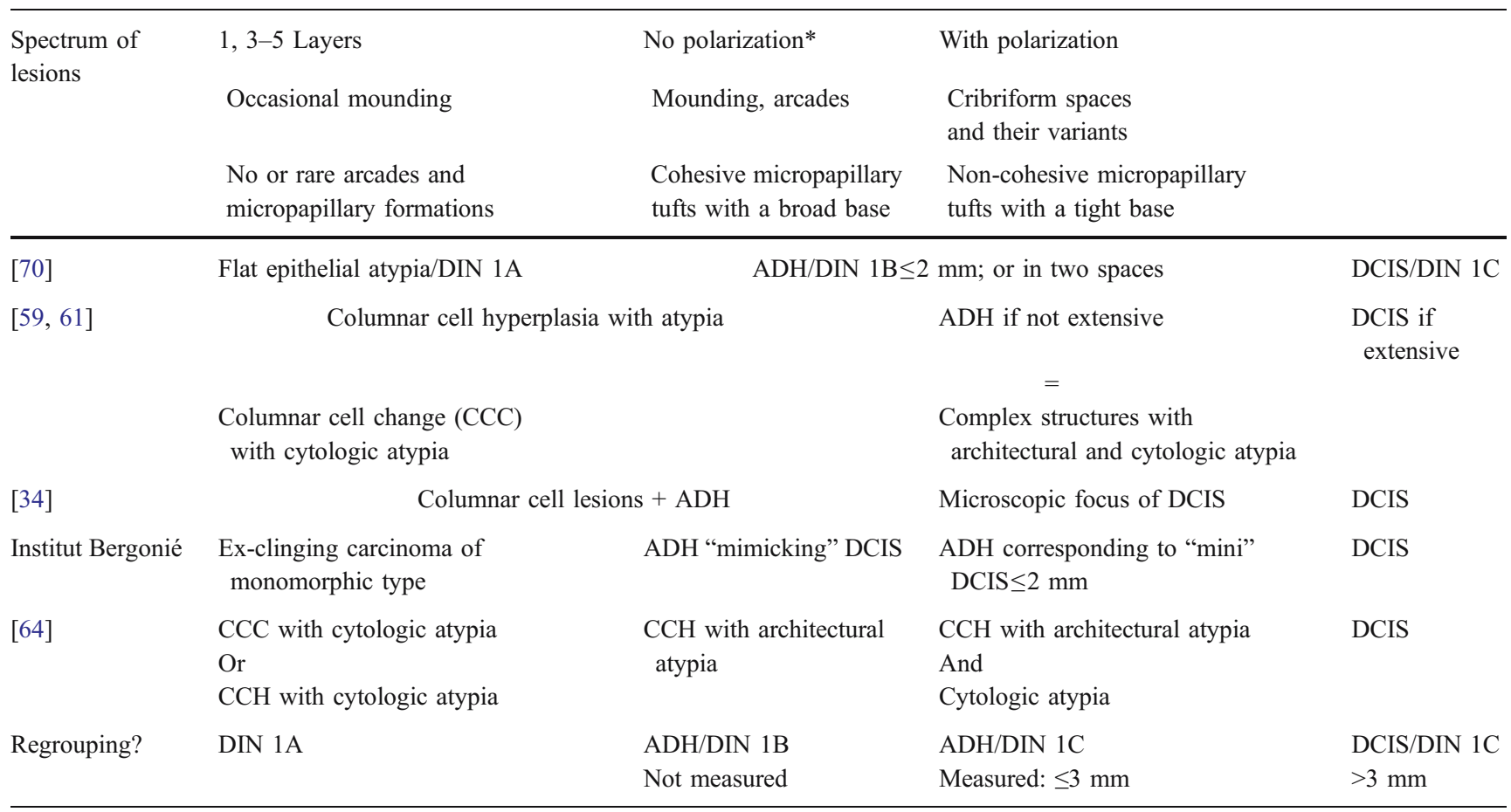

*Or incomplete polarization 
practice. Only mini foci of ADH obviously similar to lowgrade DCIS foci could be measured and classified as ADH when equal to or less than 2-3 mm [52] and as DCIS when more than $3 \mathrm{~mm}$. Although the mode of measurement in our study is not under consensus, it is simple and can been routinely applied.

Occurrence of epithelial atypia and their association with a concomitant cancer: practical considerations

In our study, the proportion of epithelial atypia is high $(23 \%)$, a result difficult to compare to others in the literature, as the methodologies used by teams are different. In the Page and Dupont case-control studies [15, 46], ADH and ALH were found in 2.1 and $1.6 \%$ of the cases, respectively. In mammographic screening programs, epithelial atypia and cancers increase as the number of biopsies performed for microcalcifications increases, especially as ACR4/ACR5 lesions are more often excised than ACR3. However, as underlined by Page [46], "the most direct relationship of epithelial atypia incidence is to slide rating." The number of slides per SB in our study (median 26) was higher than in the other studies on benign breast lesions: $1-5$ in $93 \%$ of the cases in the study of Page et al. [46] $(n=283), 3$ (range $1-25, n=674)$ in the study of Shaaban et al. [62], and a mean of 1.6 slides per $\mathrm{cm}$ of tissue $(n=199)$ in the study of Tavassoli and Norris [67]. In a recent study conducted in the south west of France in women aged between 50 and 75 with mammographically detected non-palpable breast lesions, a similar proportion of atypical lesions were found when biopsies were serially sectioned [39]. Furthermore, this high slide rating allowed the detection of small concomitant cancers in the vicinity of epithelial atypia in $31 \%$ of our cases, with a skew towards low-grade lesions (high proportions of DCIS and low-grade invasive carcinomas, especially tubular carcinomas). Our results strengthen the hypothesis that FEA and $\mathrm{ADH}$ are risk markers of low-grade cancers. This has been confirmed by the study of Simpson et al. [64] on molecular genetic profiles of CCL. In some of them, there are both a morphological and a molecular continuum in the degree of proliferation and atypia, supporting the hypothesis that "CCL are a non-obligate, intermediary step in the development of some forms of low grade in situ and invasive carcinoma." The association of epithelial atypia with a concomitant cancer in nearly one third of the cases in our study parallels previous findings concerning the frequency of cancers found in SB performed for atypia in CNB. Thus, approximately $30 \%[20,29]$ and 15 to $21 \%[5,8,14,18$, $35,45,53,63,76]$ of excisions after CNB with ADH and $\mathrm{LN}$, respectively, were proven to have cancer. Consequently, excision is recommended [45] for all patients in whom $\mathrm{ADH}$ is identified on CNB and may be justified in patients with FEA, as they are included in the spectrum of ACCL. Excision remains a controversial issue in patients with LN. Some authors have advocated it [3, 18, 33, 63], while others have rebutted it [55], especially when LN is an incidental non-extensive finding [48] with no radiologicpathologic discordance [18] and without any synchronous mass lesion [37]. SB corresponding to re-excision should be processed in its entirety by serial macroscopic sectioning $[32,65]$. When pathologic examination is exclusively focused on mammographic calcifications, the risk is to underestimate the DCIS size/extension because cancerous foci without any calcification ( $10 \%$ in our study vs $6 \%$ in Owing'study) [42] may be located at points distant from those with benign breast tissue containing calcifications.

Subsequent cancer after an initial diagnostic of epithelial atypia as a single lesion: practical considerations

In the literature, 4 to $22 \%$ (average interval 8.3 years follow-up) $[6,42,67]$ and 15 to $20 \%[16,30,56]$ of patients developed invasive carcinomas after a diagnosis of $\mathrm{ADH}$ and LN, respectively. The risk of developing cancer increases with extended follow-up, but many cancers after a diagnosis of LN have a good prognosis and a low mortality [36]. These results are difficult to compare to ours because the methodologies are different. The low probabilities of subsequent invasive cancer in our study could be due to the high slide rating, allowing the detection of small concomitant cancer that might have been missed with a low slide rating and inadequate patient management [11, 54].

In conclusion, when epithelial atypia are present, they are associated in nearly one third of the cases with a concomitant close cancer and are found as isolated lesions in nearly $23 \%$ of SB performed for microcalcifications. In practice, ADH should be more clearly defined with simple guidelines for measuring lesions. When malignancy remains equivocal and/or when sizing is difficult, it is better to classify the lesion as ADH. Epithelial atypia could be more a "risk factor" of a concomitant geographically small close cancer than a risk marker for a subsequent cancer, as they form part of a spectrum of lesions [64].

\section{References}

1. Allred DC, Mohsin SK, Fuqua SA (2001) Histological and biological evolution of human premalignant breast disease. Endocr Relat Cancer 8:47-61

2. American College of Radiology (1993-2003) Breast imaging reporting and data system (BI-RADS). American College of Radiology, Restion, VA

3. Arpino G, Allred DC, Mohsin SK, Weiss HL, Conrow D, Elledge RM (2004) Lobular neoplasia on core-needle biopsy-clinical significance. Cancer 101:242-250 
4. Azzopardi JG (1979) Problems in breast pathology. Saunders, Philadelphia

5. Berg WA, Mrose HE, Ioffe OB (2001) Atypical lobular hyperplasia or lobular carcinoma in situ at core-needle breast biopsy. Radiology 218:503-509

6. Bodian CA, Perzin KH, Lattes R, Hoffmann P, Abernathy TG (1993) Prognostic significance of benign proliferative breast disease. Cancer 71:3896-3907

7. Brogi E, Oyama T, Koerner FC (2001) Atypical cystic lobules in patients with lobular neoplasia. Int J Surg Pathol 9:201-206

8. Burak WE Jr, Owens KE, Tighe MB, Kemp L, Dinges SA, Hitchcock CL et al (2000) Vacuum-assisted stereotactic breast biopsy: histologic underestimation of malignant lesions. Arch Surg 135:700-703

9. Carter CL, Corle DK, Micozzi MS, Schatzkin A, Taylor PR (1988) A prospective study of the development of breast cancer in 16,692 women with benign breast disease. Am J Epidemiol 128:467-477

10. The Consensus Conference Committee (1997) Consensus conference on the classification of ductal carcinoma in situ. Cancer 80:1798-1802

11. Crisi GM, Mandavilli S, Cronin E, Ricci A Jr (2003) Invasive mammary carcinoma after immediate and short-term follow-up for lobular neoplasia on core biopsy. Am J Surg Pathol 27:325-333

12. de Mascarel I, Trojani M, Bonichon F, Coindre JM (1993) Histological examination of 2859 breast biopsies. Analysis of adequate sampling. Pathol Annu 28(1):1-13

13. de Mascarel I, Bonichon F, MacGrogan G, de Lara CT, Avril A, Picot V, Durand M, Mauriac L, Trojani M, Coindre JM (2000) Application of the van Nuys prognostic index in a retrospective series of 367 ductal carcinomas in situ of the breast examined by serial macroscopic sectioning: practical considerations. Breast Cancer Res Treat 61:151-159

14. Ditkoff BA, Smith SJ, Brenin D (2001) The management of lobular neoplasia identified at percutaneous core breast biopsy. Breast Cancer Res Treat 69:306 (Abstract)

15. Dupont WD, Page DL (1985) Risk factors for breast cancer in women with proliferative breast disease. N Engl J Med 312:146151

16. Dupont WD, Page D (1987) Breast cancer risk associated with proliferative disease, age at first birth, and a family history of breast cancer. Am J Epidemiol 125:769-779

17. Dupont WD, Parl FF, Hartmann WH, Brinton LA, Winfield AC, Worrell JA, Schuyler PA, Plummer WD (1993) Breast cancer risk associated with proliferative breast disease and atypical hyperplasia. Cancer 71:1258-1265

18. Elsheikh TM, Silverman JF (2005) Is follow-up surgical excision indicated when breast core needle biopsies show atypical lobular hyperplasia or lobular carcinoma in situ: a correlative study of 33 patients with review of the literature. Am J Surg Pathol 29 (4):534-543

19. Elston CW, Ellis IO (1998) The breast. In: Symmers W St C (ed) Systemic pathology, 3rd edn. Churchill Livingstone

20. Ely KA, Carter BA, Jensen RA, Simpson JF, Page DL (2001) Core biopsy of the breast with atypical ductal hyperplasia: a probabilistic approach to reporting. Am J Surg Pathol 25:1017-1021

21. Report of pathologists of the working group "Breast Cancer Screening" of the European Union (1996) European recommendations for quality assurance in the setting of mammographic screening for breast cancer. Ann Pathol 16:315-333

22. Eusebi V, Feudale E, Foschini MP, Micheli A, Conti A, Riva C, Di Palma S, Rilke F (1994) Long-term follow-up of in situ carcinoma of the breast. Semin Diagn Pathol 11:223-235

23. Fisher ER, Costantino J, Fisher B, Palekar AS, Redmond C, Mamounas E (1995) Pathologic findings from the National Surgical Adjuvant Breast Project (NSABP) Protocol B-17. Intraductal carcinoma (ductal carcinoma in situ). The National Surgical
Adjuvant Breast and Bowel Project Collaborating Investigators. Cancer 75:1310-1319

24. Fitzgibbons PL, Henson DE, Hutter RV (1998) Benign breast changes and the risk for subsequent breast cancer: an update of the 1985 consensus statement. Cancer Committee of the College of American Pathologists. Arch Pathol Lab Med 122:1053-1055

25. Foote Jr FW, Stewart FW (1945) Comparative studies of cancerous versus non cancerous breasts. Basic morphologic characteristics. Ann Surg 121:6-23

26. Fraser JL, Raza S, Chorny K, Connolly JL, Schnitt SJ (1998) Columnar alteration with prominent apical snouts and secretions: a spectrum of changes frequently present in breast biopsies performed for microcalcifications. Am J Surg Pathol 22:15211527

27. Fraser H, Raza S, Chomy K, Connoly JL, Schnitt SJ (2000) Immunophenotype of columnar alteration with prominent apical snouts and secretions (CAPSS). Lab Invest 80:21A

28. Goldstein NS, O'Malley BA (1997) Cancerization of small ectatic ducts of the breast by ductal carcinoma in situ cells with apocrine snouts: a lesion associated with tubular carcinoma. Am J Clin Pathol 107:561-566

29. Gupta A, Diaz LK, Wiley EL (2004) Atypical duct hyperplasia and lobular neoplasia diagnosed by core needle biopsy: incidence of up staging to DCIS and invasive carcinoma. Mod Path 17:33A (USCAP Abstract 123)

30. Haagensen CD, Lane N, Lattes R, Bodian C (1978) Lobular neoplasia (so-called lobular carcinoma in situ) of the breast. Cancer 42:737-769

31. Hutter RVP (1985) Goodby to "fibrocystic disease". N Engl J Med 312:179

32. International Consensus Conference (2002) Image-detected breast cancer: state of the art diagnosis and treatment. Breast J 8:70-76

33. Jacobs TW, Conolly JL, Schnitt SJ (2002) Non malignant lesions in breast core needle biopsies: to excise or not to excise? Am J Surg Pathol 26:1095-1110

34. Koerner FC (2004) Epithelial proliferations of ductal type. Semin Diagn Pathol 21:10-17

35. Liberman L, Sama M, Susnik B, Rosen PP, La Trenta LR, Morris EA, Abramson AF, Derschaw DD (1999) Lobular carcinoma in situ at percutaneous breast biopsy: surgical biopsy findings. AJR Am J Roentgenol 173:291-299

36. McLaren BK, Schuyler PA, Sanders M, Jensen RA, Simpson JF, Dupont WD, Page DL (2005) Tumor type and Nottingham grade of invasive carcinoma following atypical lobular hyperplasia on initial breast biopsy. Mod Path 18:42A, (USCAP Abstract 182)

37. Middleton LP, Grant S, Stephens T, Stelling CB, Sneige N, Sahin AA (2003) Lobular carcinoma in situ diagnosed by core needle biopsy: when should it be excised? Mod Path 16:120-129

38. Moinfar F, Man YG, Bratthauer GL, Ratschek M, Tavassoli FA (2000) Genetic abnormalities in mammary ductal intraepithelial neoplasia-flat type ("clinging ductal carcinoma in situ"): a simulator of normal mammary epithelium. Cancer 88:2072-2081

39. Monnereau A, MacGrogan G, Rabreau M, Dilhuydy MH, Demeaux JL, Ochoa A, le Groupe Anatomo Pathologistes Aquitains (GAPA), Buestel ML (2006) Evaluation de l'activité sénologique des anatomo-cyto-pathologistes aquitains avant dépostage organisé: étude prospective sur trois mois. Rev Epidémiol Santé Publique 54(4)

40. Nasser SM (2004) Columnar cell lesions: current classification and controversies. Semin Diagn Pathol 21:18-24

41. Otterbach F, Bankfalvi A, Bergner S, Decker T, Krech R, Boecker W (2000) Cytokeratin 5/6 immunohistochemistry assists the differential diagnosis of atypical proliferations of the breast. Histopathology 37:232-240

42. Owings DV, Hann L, Schnitt SJ (1990) How thoroughly should needle localization breast biopsies be sampled for microscopic 
examination? A prospective mammographic/pathologic correlative study. Am J Surg Pathol 14:578-583

43. Oyama T, Maluf H, Koerner F (1999) Atypical cystic lobules: an early stage in the formation of low-grade ductal carcinoma in situ. Virchows Arch 435:413-421

44. Oyama T, Iijima K, Takei H, Horiguchi J, Iino Y, Nakajima T, Koerner F (2000) Atypical cystic lobule of the breast: an early stage of low-grade ductal carcinoma in-situ. Breast Cancer 7:326-331

45. Pacelli A, Rhodes DJ, Amrami KK (2001) Outcome of atypical lobular hyperplasia and lobular carcinoma in situ diagnosed by core needle biopsy: clinical and surgical follow-up of 30 cases. Am J Clin Pathol 116:591, (Meeting abstract)

46. Page DL, Dupont WD, Rogers LW, Rados MS (1985) Atypical hyperplastic lesions of the female breast. A long-term follow-up study. Cancer 55:2698-2708

47. Page DL, Anderson TJ (1987) Diagnostic histopathology of the breast. Churchill Livingstone

48. Page DL, Kidd TE, Dupont WD, Simpson JF, Rogers LW (1991) Lobular neoplasia of the breast: higher risk for subsequent invasive cancer predicted by more extensive disease. Hum Pathol 22:1232-1239

49. Page DL, Rogers LW (1992) Combined histologic and cytologic criteria for the diagnosis of mammary atypical ductal hyperplasia. Hum Pathol 23:1095-1097

50. Page DL, Jensen RA (1996) Hypersecretory hyperplasia with atypia in breast biopsies. What is the proper level of clinical concern? Pathol Case Rev 1:36-40

51. Palli D, Rosselli DT, Simoncini R, Bianchi S (1991) Benign breast disease and breast cancer: a case-control study in a cohort in Italy. Int J Cancer 47:703-706

52. Pathology Reporting of Breast Disease (2005) A joint document incorporating the 3rd edn. of the NHSBSP's guidelines for pathology reporting in breast cancer screening and the 2 nd edn. of The Royal College of Pathologists. Minimum Datas for Breast Cancer Histopathology, NHSBSP Publication 58

53. Philpotts LE, Shahen NA, Jains KS et al (2000) Uncommon highrisk lesions of the breast diagnosed at stereotactic core needle biopsy: clinical importance. Radiology 216:813-817

54. Renshaw AA, Cartagena N, Derhagopian RP, Gould EW (2002) Lobular neoplasia in breast core needle biopsy specimens is not associated with an increased risk of ductal carcinoma in situ or invasive carcinoma. Am J Clin Pathol 117:797-799

55. Renshaw AA (2004) Minimal $(<$ or $=0.1 \mathrm{~cm})$ invasive carcinoma in breast core needle biopsies. Incidence, sampling, associated findings, and follow-up. Arch Pathol Lab Med 128:996-999

56. Rosen PP, Kosloff C, Lieberman PH, Adair F, Braun DW Jr (1978) Lobular carcinoma in situ of the breast. Detailed analysis of 99 patients with average follow-up of 24 years. Am J Surg Pathol 2:225-251

57. Rosen PP (1999) Breast pathology: diagnosis by needle core biopsy. Lippincott, Williams \& Wilkins, Philadelphia, PA

58. Rosen PP (1999) Columnar cell hyperplasia is associated with lobular carcinoma in situ and tubular carcinoma. Am J Surg Pathol 23:1561
59. Rosen PP (2001) Rosen's breast pathology. Lippincott, Williams \& Wilkins, Philadelphia, PA

60. Rubin E, Visscher DW, Alexander RW, Urist MM, Maddox WA (1998) Proliferative disease and atypia in biopsies performed for nonpalpable lesions detected mammographically. Cancer 61: 2077-2082

61. Schnitt SJ, Vincent-Salomon A (2003) Columnar cell lesions of the breast. Adv Anat Pathol 10:113-124

62. Shaaban AM, Sloane JP, West CR, Moore FR, Jarvis C, Williams EM, Foster CS (2002) Histopathologic types of benign breast lesions and the risk of breast cancer: case-control study. Am J Surg Pathol 26:421-430

63. Shin J, Rosen PP (2002) Excisional biopsy should be performed if lobular carcinoma in situ is seen on needle core biopsy. Arch Pathol Lab Med 126(6):697-701

64. Simpson PT, Gale T, Reis-Filho JS, Jones C, Parry S, Sloane JP, Hanby A, Pinder SE, Lee AHS, Humphreys S, Ellis IO, Lakhani SR (2005) Columnar cell lesions of the breast: the missing link in breast cancer progression? A morphological and molecular analysis. Am J Surg Pathol 29:734-746

65. Standard, Options et Recommandations (2001) Cancers du sein non métastatiques, vol 3. FNCLCC, p 29

66. Stomper PC, Cholewinski SP, Penetrante RB, Harlos JP, Tsangaris TN (1993) Atypical hyperplasia: frequency and mammographic and pathologic relationships in excisional biopsies guided with mammography and clinical examination. Radiology 189:667-671

67. Tavassoli FA, Norris HJ (1990) A comparison of the results of longterm follow-up for atypic intraductal hyperplasia and intraductal hyperplasia of the breast. Cancer 65:518-529

68. Tavassoli FA (1998) Ductal carcinoma in situ: introduction of the concept of ductal intraepithelial neoplasia. Mod Path 11:140-154

69. Tavassoli FA (1999) Pathology of the breast, 2nd edn. Appleton and Lange

70. Tavassoli FA, Devilee P (2003) Pathology and genetics. In: Tumours of the breast and female genital organs. Word Health Organization classification of tumours, pp 60-76

71. Trojani M (1988) Atlas en couleur d'histopathologie mammaire. Maloine, Paris

72. Tsuchiya S (1998) Atypical ductal hyperplasia, atypical lobular hyperplasia and interpretation of a new borderline lesion. Jpn J Cancer Clin 44:548-555

73. Types histologiques des tumeurs du sein (1981) In: Classification Histologique Internationale des Tumeurs. Organisation Mondiale de la Santé, Genève

74. Weidner N (1995) Malignant breast lesions that may mimic benign tumors. Semin Diagn Pathol 12:2-13

75. Wellings SR, Jensen HM, Marcum RG (1975). An atlas of subgross pathology of the human breast with special reference to possible precancerous lesions. J Natl Cancer Inst 55:231-273

76. Zhang RR, O'Hea BJ, Brebbia JR et al (2001) Atypical lobular hyperplasia or lobular carcinoma in situ on large core needle biopsy of the breast: is surgical excision necessary? Am J Clin Pathol 116:610 (Meeting abstract) 